\title{
Origin identification of migratory pests (European Starling) using geochemical fingerprinting
}

\author{
Upama Khatri-Chhetri $^{\text {Corresp., } 1}$, John G. Woods ${ }^{2}$, Ian R. Walker ${ }^{2}$, P. Jeff Curtis ${ }^{3}$ \\ ${ }^{1}$ Agriculture, Food and Nutritional Science, University of Alberta, Edmonton, Alberta, Canada \\ 2 Biology, University of British Columbia, Kelowna, British Columbia, Canada \\ 3 Earth, Environmental and Geographic Sciences, University of British Columbia, Kelowna, British Columbia, Canada \\ Corresponding Author: Upama Khatri-Chhetri \\ Email address: upama@ualberta.ca
}

The European Starling (Sturnidae: Sturnus vulgaris L.) is an invasive bird in North America where it is an agricultural pest. In British Columbia (Canada), the starling population increases in orchards and vineyards in autumn, where they consume and damage ripening fruits. Starlings also cause damage in dairy farms and feedlots by consuming and contaminating food and spreading diseases. Damage can be partly mitigated by the use of scare devices, which can disperse flocks until they become habituated. Large-scale trapping and euthanizing before starlings move to fields and farms could be a practical means of preventing damage, but requires knowledge of natal origin. Within a small $\left(20,831 \mathrm{~km}^{2}\right)$, agriculturally significant portion of south-central British Columbia, the Okanagan-Similkameen region, we used 21 trace elements in bone tissue to discriminate the spatial distribution of juvenile starlings and to reveal the geographic origin of the problem birds in fall. Stepwise discriminant analysis of trace elements classified juveniles to their natal origin (minimum discrimination distance of $12 \mathrm{~km}$ ) with $79 \%$ accuracy. In vineyards and orchards, the majority (55\%) of problem birds derive from northern portions of the valley; and the remaining $45 \%$ of problem birds were a mixture of local and immigrant/unassigned birds. In contrast, problem birds in dairy farms and feedlots were largely immigrants/unassigned (89\%) and $11 \%$ were local from northern region of the valley. Moreover, elemental signatures can separate starling populations in the Valley yielding a promising tool for identifying the geographic origin of these migratory birds. 


\section{ORIGIN IDENTIFICATION OF MIGRATORY PESTS (EUROPEAN STARLING) USING GEOCHEMICAL FINGERPRINTING}

\section{Upama Khatri-Chhetri', John G. Woods², Ian R. Walker², P. Jeff Curtis ${ }^{3 *}$}

${ }^{1}$ Agriculture, Food and Nutritional Science, University of Alberta, Edmonton, Canada

${ }^{2}$ Biology, University of British Columbia, Kelowna, British Columbia, Canada

${ }^{3}$ Earth, Environmental and Geographic Sciences, University of British Columbia, Kelowna, British Columbia, Canada

Corresponding author: Upama Khatri-Chhetri (upama@ualberta.ca); Jeff Curtis (jeff.curtis@ubc.ca) 


\section{Abstract}

2

3 America where it is an agricultural pest. In British Columbia (Canada), the starling population

4 increases in orchards and vineyards in autumn, where they consume and damage ripening fruits.

5 Starlings also cause damage in dairy farms and feedlots by consuming and contaminating food

6 and spreading diseases. Damage can be partly mitigated by the use of scare devices, which can

7 disperse flocks until they become habituated. Large-scale trapping and euthanizing before

8 starlings move to fields and farms could be a practical means of preventing damage, but requires

9 knowledge of natal origin.

11 Columbia, the Okanagan-Similkameen region, we used 21 trace elements in bone tissue to

12 discriminate the spatial distribution of juvenile starlings and to reveal the geographic origin of

13 the problem birds in fall. Stepwise discriminant analysis of trace elements classified juveniles to

14 their natal origin (minimum discrimination distance of $12 \mathrm{~km}$ ) with $79 \%$ accuracy. In vineyards

15 and orchards, the majority (55\%) of problem birds derive from northern portions of the valley;

16 and the remaining $45 \%$ of problem birds were a mixture of local and immigrant/unassigned

17 birds. In contrast, problem birds in dairy farms and feedlots were largely immigrants/unassigned

$18(89 \%)$ and $11 \%$ were local from northern region of the valley. Moreover, elemental signatures

19 can separate starling populations in the Valley yielding a promising tool for identifying the

20 geographic origin of these migratory birds. 


\section{Introduction}

European starling (Sturnus vulgaris L.) is one of the most successful non-native species in North America (Vuilleumier 2009). A few hundred birds were introduced in New York City in 1890 (David 2010; Kerpez T. A. 1990; Linz et al. 2007). Surviving descendant birds spread rapidly throughout North America in the following years (Cabe 1993; Linz et al. 2007) and have now grown to a population of many millions. The perception of starlings changed along with population size from a beautiful, robin size 'Chunky' songbird into an aggressive and costly pest. Starling is listed as one of the three worst invasive birds in the World Conservation Union List of '100 of the world's worst invasive alien species' (Lowe S., Browne M., Boudjelas S. 2004). According to the International Union for Conservation of Nature, its conservation status is considered to be of least concern on the basis of its probability of extinction. It is considered as an agricultural pest, especially in fruit crops such as cherries, berries, and grapes (Pimentel et al. 2005, BCGA 2013; Conover et al. 2007; Virgo 1971).

The migration pattern of European starlings varies regionally and individually. In some areas, most of the breeding individuals are sedentary (Kessel 1953; Suthers 1978). Some individuals migrate in some years and not in others. Some juveniles migrate, but even their nest mates (siblings) might not (Kessel 1953). Generally, spring migration occurs between midFebruary to end of March and fall migration occurs from September to December (Dolbeer 1982; Kessel 1953). Starlings can cover up to $1,000-1,500 \mathrm{~km}$ if needed in search of food especially during winter (Linz et al. 2007).

The Okanagan-Similkameen region is a nationally significant agricultural region in Canada due to climatic and geological suitability. The valley is ideal for several tree fruits such as apples, peaches, and other soft fruits, like cherries, berries, and grapes, and for livestock 
44 operations including both dairy farms and beef cattle feedlots. Around $97.5 \%$ of British

45 Columbia's vineyard and 98\% of the province's apples and grapes are grown in the south-central

46 Okanagan-Similkameen region region (Neuhauser 2013; BC Growers 2015). In the northern

47 Okanagana region, livestock operations, such as dairy farms and feedlots, grains and forage crops predominate (BC Growers 2015; BCGA 2013). The cold short winters, warm summers, rural/urban interface, and availability of year-round food sources in the Okanagan-Similkameen region provide excellent starling habitat.

Large flocks of up to 1000s starlings are known to destroy fruits in the vineyards, orchards and depredate cattle feed at dairy farms (Glahn 1981). Annually around $\$ 800$ million USD worth of agricultural crops were destroyed by starlings in the United States, based on crop losses of \$5/ha (Pimentel et al. 2000). In livestock facilities, starlings consume and contaminate around 15-20 tons of cattle feed per day (Linz et al. 2007). Annually, around \$3 million USD per year is lost in vineyards and tree fruit farms in the Okanagan-Similkameen region alone (BCGA 2012).

A Starling Control Program (SCP) was initiated in the Okanagan-Similkameen region of British Columbia in 2003 (BCGA 2010) to control the starling population and the damage they cause. Agricultural industries, environmental agencies, and regional districts supported the 61 program (BCGA 2010). The SCP traps birds in various locations in the Okanagan-Similkameen region throughout the year. From 2003 to 2013 around 544,000 birds were trapped by the control program (OSSCP 2014). Although the control program has been trying to reduce the starling population by aggressively trapping all year round, numbers appear to be increasing from 996 to 23592 from 1974 to 2013 (Christmas Bird Count, Birds Canada), especially in the fall season due to migration and natal dispersal. Starling numbers increase in vineyards and orchards in fall 
67 (BCGA 2013), but dispersion and movement patterns of starlings has not been well understood

68 in the Okanagan-Similkameen region. It is necessary to find the origin of these migrant birds to

69 enhance program effectiveness. Thus, understanding the natal origin and movement pattern of

70 migratory pests, like starlings, is important for developing successful management (Cabe 1993;

71 Neuhauser 2013). The main objective of this research is to identify the origin of the migratory

72 starlings using a geochemical (trace element) fingerprinting approach in the Okanagan-

73 Similkameen region so that starling might be managed at sources.

Biogeochemical markers such as stable isotopes (Hobson 1999, 2005a, 2005b; Szép et al.

75 2009) and trace elements analyses (Szép et al. 2003; Szép et al. 2009) are potential methods to

76 trace the origin and migration of such birds because the markers are indicators of the

77 environment of origin. Starlings can disperse long distances and retain stable isotopes and trace

78 element signatures in tissues reflecting natal food (Hobson 1999), location, and habitat (Szép et al. 2009). These chemical signatures can be applied as tools to reconstruct animal movement pathways (Ethier et al. 2013).

We chose trace elements over light isotope ratios for this study for two reasons. First, isotope ratios in birds can be homogeneous for thousands of kilometres (Inger and Bearhop 2008), an order of magnitude larger than the Okanagan-Similkimeen region. In contrast, the province of British Columbia and Okanagan-Similkameen region are geochemically diverse across spatial scales of tens of kilometres or less (Okulitch 2013), making trace elements potentially much more sensitive for tracking regional starling movements (Neuhauser 2013).

87 Second, trace elements can provide a higher specificity than isotopes because of the larger number of potential variables (Szép et al. 2009). We hypothesized that the elemental 
90 element signatures in their tissues from their diet, and these signatures reflect the chemical

91 composition of the area in which the tissue was generated, or keep the record of past feeding

92 history as recorded in long turnover tissues (Hobson 1999; Szép et al. 2009).

93 We used samples of starling leg bone tissue (tarsometatarsus) commonly known as tarsus

94 or metatarsus to fingerprint natal origins of individual starlings. Feather tissue is more

95 convenient to use but we chose bone because feathers moult seasonally shedding the evidence of

96 natal origin, whereas the turnover rate of bone tissue is as much as 30 years (Tieszen et al. 1983,

97 Lanocha and Kalisinska 2012). Bone tissues are very useful for origin analysis as the mineral

98 phase in the bone matrix grows rapidly when an individual is a juvenile and then turns over very

99 slowly (Neuhauser, 2013). Most bone mass consists of type I collagen and apatite (a mineral

100 composed mainly of calcium and phosphate) (Boonen et al. 2010). The bone mineralization is

101 analogous to the geological mineral (Boonen et al. 2010) and is known as hydroxyapatite, $\mathrm{Ca}_{5}$

$102\left(\mathrm{PO}_{4}\right)_{3} \mathrm{OH}$ (Boskey 2007; Pasteris, Wopenka et al. 2008). Other cations and anions easily

103 substitute into the mineral matrix of apatite. Thus, other elements, derived from the diet can be

104 incorporated into bone to create a fingerprint, representing the food an individual has ingested

105 (Grynpas et al. 1993). The decision of using bone is also supported by an earlier study of six

106 European starling tissues (bone, liver, heart, muscle, brain, and feather) that identified bone as

107 the tissue for statistically separating populations of starlings across much of its range in British

108 Columbia (Neuhauser 2013).

109 In this study, we evaluated the geochemical fingerprint of juvenile starlings throughout

110 the Okanagan-Similkameen region, and compared these signatures to that of problem birds

111 caught in the fall trapped in fruit crops in and dairy farms. By fingerprinting starling natal origin, 
112 appropriate management to reduce starling populations could be implemented in focused areas to

113 reduce the damage created by starlings.

\section{Materials and Methods}

\section{Study Area}

116 British Columbia (BC) is the western-most province of Canada and has high geological

117 diversity in rock types (Canada 2012) (Fig. 1). The Okanagan-Similkameen region in south-

118 central British Columbia is about $200 \mathrm{~km}$ long and $20 \mathrm{~km}$ wide (Fig. 1). It lies in between the

119 Columbia and Cascade Mountain ranges in the southern interior of BC. The valley bedrock is

120 comprised of volcanic, sedimentary, metamorphic and intrusive rocks (Okulitch 2013). Southern

121 Okanagan-Similkameen region is heterogeneous, made up of volcanic, metamorphic, plutonic,

122 and sedimentary rocks, and overlain by glacial sediments (Okulitch 2013). Central Okanagan is

123 made up lava, andesite with quartz-filled amygdales. The northern Okanagan is made up of

124 Paleozoic phyllite, argillite, schist, amphibolitic, quartzite, carbonaceous, micaceous chlorite and 125 other minor constituents (Table S1) (Okulitch 2013).

126 Starling habitat is generally the lower elevation portion of a long valley, approximately

127 between 300 and $700 \mathrm{~m}$ elevation. Above $700 \mathrm{~m}$, the valley rises quickly to a plateau of $>1200$

$128 \mathrm{~m}$ (Fig. S1), greatly constraining distribution and likely movement and migration to a relatively

129 small area (Fig. S1).

\section{Sampling}

131 Sampling was performed in summer (May-July) and in fall/winter of 2015. In summer,

132 only juveniles, having little prior chance to disperse beyond their natal habitat, were collected to

133 establish fingerprints of source populations. Thus, their bone tissue will reflect the elemental

134 fingerprint of the sites where they were collected. To make our trace element fingerprint library 
135 more representative, juveniles were collected from almost all the Okanagan-Similkameen

136 cities/towns, and lands used for different agricultural activities, such as vineyards, orchards,

137 dairy farms, feedlots, grasslands, and landfill sites.

138 In fall, problem birds (both adult and juveniles ( $<$ 1year) were collected in

139 vineyard/orchards and dairy farms/feedlots. The age of the birds was determined from their

140 plumage (Szép et al. 2003; Szép et al. 2009). Additionally, aging by plumage was validated by

141 the chronology of skull development (skull ossification - skulling) in juveniles (McKinney,

142 2004). Five randomly selected samples, which were considered as juvenile through plumage,

143 were dissected to observe evaluate developmental stage by skulling (Mueller and Weise 1996).

144 These starlings are considered pests and hereafter referred to as "problem birds".

145 Sampling was performed in collaboration with the Starling Control Program (SCP),

146 British Columbia Grapesgrowers' Association (BCGA). A team of professional trappers

147 contracted by the BCGA, has been trapping and euthanizing starlings following the guidelines of

148 the Canadian Council on Animal Care every year. We obtained frozen sample from SCP trappers

149 and each individual bird is considered as a single sample. Altogether, 105 juveniles were

150 collected from ten different locations situated at distances from 12 to $190 \mathrm{~km}$ apart throughout

151 the Okanagan-Similkameen region in 2015. The number of juvenile samples collected in summer

152 varied depending on availability at each location, 20 from Kelowna, 10 from Hullcar, 10 from

153 Salmon Arm, 9 from Armstrong, 9 from Mara, 18 from Vernon, 10 from Oliver, 8 from

154 Osoyoos, 6 from Penticton and 5 from Keremeos. In fall, 118 problem birds (including young

155 adults $<1$ year, $\mathrm{n}=20$; and adults: $1+$ years, $\mathrm{n}=98$ ) were collected from vineyards/orchards and

156 dairy farms and feedlots having major starling problem. Some of the problem bird sampling

157 locations are the same where juveniles were collected like Vernon $(n=4)$, Pentiction $(n=27)$, 
158 Keremeos $(\mathrm{n}=5)$, Kelowna $(\mathrm{n}=14)$, and Oliver $(\mathrm{n}=15)$; however, Okanagan falls $(\mathrm{n}=4)$,

159 Summerland $(n=30)$, Coldstream $(n=10)$, and Lumby $(n=9)$ were added in fall. These locations

160 spread across Okanagan-Similkameen region from south to north (Fig. 1).

\section{Sample preparation}

162 Samples were prepared by methods described by Norris et al. (2007) with some

163 modification. Briefly, the bone was cleaned by removing outer skin and marrow. Bones were

164 washed repeatedly with ultra-pure water $\left(18 \mathrm{M} \Omega \mathrm{cm}^{-1}\right)$, dried at room temperature $\left(20{ }^{\circ} \mathrm{C}\right)($ Szép

165 et al. 200) and weighed. The clean fragments of the bone sample, weighing between $30 \mathrm{mg}$ to 80

166 mg each, were put separately into Teflon tubes. Trace element grade concentrated nitric acid

167 (2ml) was added to each tube and placed in a heating block $75^{\circ} \mathrm{C}\left( \pm 5^{\circ} \mathrm{C}\right)$ until the bone was

168 completely dissolved. Samples were then cooled to room temperature, and then one milliliter of

169 trace metal grade hydrogen peroxide was added to further digest the dissolved organic

170 compounds (Norris et al. 2007). Samples were then evaporated on a hot plate at $85^{\circ} \mathrm{C}\left( \pm 5^{\circ} \mathrm{C}\right)$

171 (Szép et al. 2003; Neuhauser 2013). After cooling, $2 \mathrm{ml}$ of $1 \% \mathrm{HNO}_{3}$ with 1 ppb indium internal

172 standard was added to each vial to dissolve the residue over a period of 2 hours at room

173 temperature.

174 Samples were transferred quantitatively with three washes of the $\mathrm{HNO}_{3}$ indium solution

175 into acid-washed high-density polyethylene tubes to a final volume of $10 \mathrm{~mL}$ ( Norris et al.

176 2007; Neuhauser 2013). Sample blanks were prepared in the same way for every set of digestions

177 to monitor contamination (Donovan et al. 2006; Norris et al. 2007; Szép et al. 2009). Sub-

178 samples were further diluted 100-fold with $1 \mathrm{ppb}$ indium-1\% $\mathrm{HNO}_{3}$ for ICP-MS analysis and 5

179 and 10 fold with 1 ppm yttrium- $1 \% \mathrm{HNO}_{3}$ for ICP-OES analysis. Samples were diluted to fall

180 within the detection limits of the instruments. 


\section{Trace element analysis}

182 We measured 21 elements: aluminium $(\mathrm{Al})$, silver $(\mathrm{Ag})$, barium $(\mathrm{Ba})$, calcium $(\mathrm{Ca})$,

183 cadmium $(\mathrm{Cd})$, cobalt $(\mathrm{Co})$, chromium $(\mathrm{Cr})$, copper $(\mathrm{Cu})$, molybdenum $(\mathrm{Mo})$, manganese $(\mathrm{Mn})$,

184 lead $(\mathrm{Pb})$, sulphur $(\mathrm{S})$, scandium $(\mathrm{Sc})$, selenium $(\mathrm{Se})$, tin $(\mathrm{Sn})$, strontium $(\mathrm{Sr})$, vanadium $(\mathrm{V})$, zinc

$185(\mathrm{Zn})$, magnesium $(\mathrm{Mg})$, sodium $(\mathrm{Na})$, and potassium $(\mathrm{K})$ in bone tissue. The elements were

186 selected on the basis that they are present at levels high enough for reliable quantification, and

187 could also vary in space.

188 Seventeen of the 21 elements were analysed by Thermo-Fisher Element XR sector field

189 Inductively Coupled Plasma-Mass Spectrometer (ICP-MS) (Poesel et al. 2008; Neuhauser 2013).

190 A subset of four highly-abundant elements, $\mathrm{Ca}, \mathrm{Mn}, \mathrm{Na}$, and K, were analysed via a Thermo-

191 Electron Corporation, iCAP 6000 Series XR Inductively Coupled Plasma-Optical Emission

192 Spectrometer (ICP-OES) (Szép et al. 2003; Szép et al. 2009; Neuhauser 2013). For ICP-MS,

193 elements were analysed in either low resolution or medium resolution mode to resolve

194 polyatomic interferences. Both instruments were calibrated by external multi-element standards.

195 Four different concentrations of multi-element standards were run to produce calibration curves

196 (Poesel et al. 2008). Indium (Norris et al. 2007) and yttrium (Neuhauser 2013) were used as an

197 internal standard for ICP-MS and ICP-OES respectively to correct for instrument drift, sample

198 density and to improve accuracy and repeatability. The blank and reference solutions were run at

19920 -sample intervals throughout the analysis. Three replicate analyses were done for each sample.

200 Relative Standard Deviation (RSD) of the analysis was between 1-2\%.

201 Statistical Analysis of Data

202 The elemental concentration was normalized to the concentration of calcium rather than

203 mass to minimize variability in the ratio of mineral:collagen content. The collagen structure of 
204 bone bonds relatively poorly with metals, whereas the mineral apatite substitutes cations and

205 anions relatively easily into its structure. As birds develop, the relative content of apatite

206 increases (Rogers and Zioupos 1999; Currey 2004; Currey et al. 2004; Pasteris et al. 2008).

207 Normalizing with calcium, therefore, removes this variability due to collagen content. After

208 calcium normalization, the data were then standardized via z-scoring to prevent individual

209 elements from having a disproportionate influence on the groupings derived from multivariate

210 analyses (Fowler et al.1998; Norusis 2016).

211 A multivariate analysis of variance (MANOVA) was used to analyse trace element

212 profiles of juvenile bone tissue collected in different locations (Norusis 2016). A multiple

213 discriminant analysis (Hair et al. 2010) of juvenile samples was performed to discard elements

214 (variables), which were little related to group distinction, and also to develop the predictive

215 model of group membership based on trace elements (chemical profile of bone). A discriminant

216 function (equation) was developed based on the linear combination of the predictor variables

217 (trace elements) that provides the best discrimination (correctly separating individual birds)

218 among the predetermined groups (Lachenbruch and Goldstein 1979; Greenough et al. 1997; Szép

219 et al. 2009). The predetermined groups were the sites where the juvenile starlings were caught.

220 The stepwise method and Mahalanobis distance (Hair et al. 2010) were used for the analysis

221 because of the large number of variables (20 different element concentrations).

222 The stepwise method looks at each element (variable), one at a time, and determines

223 which element is the best predictor of group membership, and ultimately generates the best set of

224 variables to predict group membership. Cross-validation assessed the success of the proper bird

225 groupings via the discriminant function and rules. In order to classify objectively the problem

226 birds with respect to origin, the value obtained from each function for each problem bird was 
227 normalized (ratio of sample/ratio of centroid) by the centroid value of each site. Thus, if an

228 individual problem bird were to lie at the centroid for a particular site, its value with respect to

229 that site would be one. Each bird's probable origin was identified by how closely that bird's

230 normalized value approximated the centroid values of each site. For some of the problem birds,

231 the discriminant function value was too high to assign a specific juvenile source population. For

232 such birds, we have categorized them as immigrant/unassigned birds.

233 Cluster analysis (Hartigan 1975) was performed to evaluate the spatial separation of the

234 elemental fingerprint of starlings and the identification of likely immigrants. In this study, the

235 ward.D method (Ward 1963; Murtagh and Legendre 2014) with Euclidean distance measures

236 was used for analysis, which provided better separation of individual birds with similar

237 signatures and geographic location. Additionally, an average method with correlation distance

238 was used to compute a test of significance of the clusters (by calculating the p-value of the

239 cluster). The R package "pvclust" (Suzuki and Shimodaira 2014) was used; it uses bootstrap

240 resampling techniques to compute the p-value for each cluster. This method generates thousands

241 of bootstrap replications by randomly sampling elements of the data. For each of the clusters,

242 Approximately Unbiased (AU) and Bootstrap Probability (BP) values were calculated. The AU

243 probability values ( $\mathrm{p}$-values) are computed by multiscale bootstrap resampling where AU $\geq 95 \%$

244 are considered to be strongly supported by the data, while BP corresponds to the frequency that

245 the cluster is identified in bootstrap copies (Suzuki and Shimodaira 2014).

246 Statistical analysis was conducted in SPSS ver. 24.0 and R statistical software version

247 3.3.1 (R Development Core Team n.d.) with the cluster (Maechler et al. 2017) and pvclust

248 (Suzuki and Shimodaira 2014) packages. Map projections of data were done in ArcGIS 10.4.

249 Results 
250 Spatial separation of source population of starlings in the Okanagan-Similkameen region

251 The source population trace element fingerprint library for the Okanagan-Similkameen

252 region was developed from juvenile starlings collected from 10 different locations. Multivariate

253 comparison of 20 elements in the juvenile $(\mathrm{n}=105)$ population using MANOVA shows there is a

254 significant difference in the trace elemental composition of juvenile bone among locations

255 (Wilks' $\lambda<0.0001, \mathrm{~F}=6.655, \mathrm{df}=180,645.230$, power $=1, \mathrm{p}<0.0001$ ).

256 A stepwise discriminant analysis of 20 trace elements based on the juveniles $(n=105)$

257 collected at 10 different locations, provided four canonical discriminant functions with

258 significantly high eigenvalues $(>1)$, and canonical correlations $(\mathrm{rc}>0.70)$, that separated juvenile

259 samples from respective sites (Wilks' $\lambda=0.001,0.11,0.73, \chi^{2}=633,428,247, \mathrm{p}<0.0001$ ) (Fig.

260 2). Ten elements (K, Mg, Na, $\mathrm{Ag}, \mathrm{Cd}, \mathrm{Ba}, \mathrm{Sc}, \mathrm{Cr}, \mathrm{Cu}$, and $\mathrm{Se}$ ) out of 20 , were used as the best

261 predictor variables in discriminating group membership. The probabilities of correctly

262 classifying juveniles to their respective locations using stepwise discriminant analysis are shown

263 in Table 1. The table shows the predicted classification (group membership) using cross-

264 validation from different locations compared to the apparent or actual observation. The overall

265 probability of correctly classifying juveniles was $79 \%$ ( $\mathrm{P}<0.0001$, Press's Q; Table 1$)$. The

266 juveniles were grouped $67 \%-100 \%$ correctly, with Osoyoos as an exception. Only $25 \%$ of the

267 Osoyoos juveniles were correctly grouped by location. Mostly the misclassification pattern that

268 occurred was among nearby locations. For example, a high rate of misclassification, $30 \%$ and

$26937 \%$ (Table 1), occurred between Oliver and Osoyoos ( $\sim 17 \mathrm{~km}$ apart), 33\% between Penticton

270 and Keremeos ( $\sim 45 \mathrm{~km}$ apart), and 22\% and 33\% between Mara and Armstrong (Table 1).

271 Hence, almost all the misclassification occurs between sites that are very close to each other,

272 with one exception, between Osoyoos and Vernon in 2015 (37\%, 165 km apart, Table 1). 
274 method) grouped juveniles from different sites into different clusters, even separating individuals

275 derived from locations $\leq 12 \mathrm{~km}$ (Fig. 3) apart. Since there is no particular rule for choosing the

276 height in the Ward.D method dendrogram, the rule of thumb height of 10 was applied. Between

$27733-100 \%$ of juveniles from the same locations were grouped together at the height of 10 (Fig.

278 3). Approximately unbiased (AU) values obtained via the average method were used to test the

279 significance of the clusters. Ten major significant clusters with red boxes (AU p-value $>0.95$ )

280 separated juveniles from different geographic locations (Fig. S2). Thus, juvenile grouping with

281 respect to geographic location in cluster analysis supports the predicted membership results

282 derived from stepwise discriminant analysis. Thus, our results are robust to different multivariate

283 statistical methods.

284 Identification of the source population of problem birds in the Okanagan-Similkameen 285 region

The source population of problem birds was identified by comparing their trace element

287 fingerprint with the juvenile fingerprint library. Cluster analysis of all birds including both

288 juvenile $(\mathrm{n}=105)$, and problem birds $(<1$ year adults $(\mathrm{n}=20)$, and $1+$ year adults $(\mathrm{n}=98))$ depicts

289 two distinct clusters, separating most problem birds into one cluster and another cluster

290 comprising a mix of the remaining problem birds and juvenile birds (Fig.4). Around half of the

291 problem birds $(\mathrm{n}=52,44 \%)$ clustered separately, indicating chemical composition distinct from

292 the juvenile fingerprint library (Fig. 4). Problem birds having trace element fingerprints distinct

293 from the Okanagan-Similkameen populations (doesn't match our library) were considered as

294 immigrant/unassigned birds, likely originating from unsampled sites within the Valley or from

295 outside of the Valley. 
297 Okanagan-Similkameen region, the same four canonical discriminant functions were used. The

298 first function explained $44.2 \%$ of the total variance among locations. The second function

299 explained $33.0 \%$, and the third and fourth explained $11.7 \%$ and $6.1 \%$, respectively of the total

300 variance among locations. The problem birds collected in fall were divided into two groups.

301 First, problem birds collected in vineyards and orchards and second, those collected at dairy

302 farms and feed lots. The majority (55\%) of problem birds caught in vineyards and orchards were

303 consistent with trace element signatures of juvenile birds from the North Okanagan. Specifically,

304 the highest contributing site was Vernon (41\%) (Fig. 5). The remaining 45\% of problem birds

305 were a mixture of local and immigrant/unassigned birds (29\% southern local, $2 \%$ central local),

$30614 \%$ of problem birds in vineyards and orchards were immigrants/unassigned (Fig. 5). In

307 contrast to vineyards and orchards, the problem birds caught on dairy farms and feedlots were

308 largely immigrants/unassigned (89\%) and only 11\% were local from northern site (Vernon) (Fig. $3095)$.

310 Discussion

311 Spatial separation of starlings

312 Resolving populations in space revealed distinct trace elemental signatures within the

$313200 \mathrm{~km}$ length of the Okanagan-Similkameen region. The spatial separation of starling in this

314 study using bone tissue trace elemental fingerprinting is comparable to spatial separation of other

315 birds at scales ranging between kilometers to continental distances using feather tissue trace

316 elemental fingerprinting (Poesel et al. 2008; Szép et al. 2009). For example, white-crowned

317 sparrow (Zonotrichia leucophrys F.) samples collected from four dialect populations were 
318 distinguished within 400km (Poesel et al. 2008). Similarly, sand martin (Riparia riparia L.) and

319 barn swallow (Hirundo rustica L.) populations were separated within and between continents

320 (i.e., across Europe and between European and African moulting sites) (Szép et al. 2003; Szép et

321 al. 2009). In our study, the shortest distance separating sites with distinct chemical signatures

322 was $12 \mathrm{~km}$ (between Vernon and Armstrong).

323 Site-specificity of the elemental compositions of bones from juvenile starling is similar to

324 analyses of natal origin from nestlings and juvenile sand martins (Riparia riparia L.) (Szép et al.

325 2003) and for western sandpiper using feather tissue (Calidris mauri Cabanis; Norris et al. 2007).

326 Moreover, a high degree of similarity in feeding and foraging habitat of juveniles could be

327 factors maintaining the similarity of juvenile bone trace element composition in local

328 populations. Since most juveniles collected within sites were chemically similar, it appears that

329 these juveniles had not dispersed. Thus, the juvenile fingerprint library adequately represents the

330 fingerprints of source populations at particular sites in the valley.

331 The chemical signature of a few juvenile birds caught within a site matched with

332 fingerprints from other sites according to the predicted group membership derived from

333 discriminant analysis. Such misclassification of juveniles among nearby sites such as Oliver and

334 Osoyoos may have arisen due to overlapping foraging ranges of the juveniles or adults feeding

335 chicks, geological similarity between nearby sites, similar agricultural practices and food choice.

336 These mechanisms are not mutually exclusive and all may have been operating. Finally,

337 misclassification noted in a few birds between the sites that are 100s of kilometers apart

338 geographically might be due to differences in food choice and early short distance dispersal or

339 geochemical similarity between remote sites. 
341 similar to the degree of differentiation reported for shearwaters (Calonectris Cory \& Oustalet)

$34275-89.9 \%$ (Gómez-Díaz and González-Solís 2007) and lower than that in white-crowned

343 sparrows 100\% across $400 \mathrm{~km}$ (Poesel et al. 2008). The dissimilarity of chemical composition

344 among sites within the Okanagan-Similkameen region may be due to geologic factors (Ethier et

345 al. 2013), and/or hydrologic factors including irrigation (Poesel et al. 2008). The underlying

346 geology of the Okanagan-Similkameen watershed is very diverse within small spatial scales

347 (Okulitch 2013).

348 Similarly, soil chemistry is non-uniform over the landscape (Goitom Asfaha et al., 2011).

349 Water, mineralogy and soil microbiology affect soil chemistry. Solutes present in soil water can

350 be derived from weathering of rocks and minerals locally or could have come from water

351 (precipitation and irrigation). The trace elements move from minerals to soil water (Galgano,

352 Favati, Caruso, Scarpa, \& Palma, 2008) where they are taken up by plants. In turn, plants form

353 the base of the food web, eventually accumulating in animal tissues, forming a unique marker.

354 The trace element availability in soil can be further modified by factors like soil $\mathrm{pH}$, water

355 content and porosity (Kelly, Heaton, \& Hoogewerff, 2005; Kim \& Thornton, 1993).

356 Trace element composition in bone tissues can yield a very specific biogeochemical

357 marker. Out of 21 elements analysed, ten elements (K, Mg, $\mathrm{Na}, \mathrm{Ag}, \mathrm{Cd}, \mathrm{Ba}, \mathrm{Sc}, \mathrm{Cr}, \mathrm{Cu}$, and $\mathrm{Se}$ )

358 were used in a discriminant analysis that classified juveniles source populations. All are cations

359 (Se is also an oxyanion) and could potentially substitute into apatite. For example, $\mathrm{Pb}$ substitutes

360 for $\mathrm{Ca}$ in hydroxyapatite in bone with a turnover rate ranging from $1-8 \%$ per year depending on

361 the type of bone tissue (Martin, Naftel, Nelson, \& Sapp, 2007). The shortlisted elements from 
362 the discriminant analysis are therefore a mixture of those elements, which could easily be present

363 in bone, and could also vary in space.

364 Assigning problem starlings to natal populations

365 Problem birds were assigned to potential natal populations through discriminant analyses.

366 However, some of the problem birds could not be assigned to its source population and were

367 designated as immigrant/unassigned problem birds. Failure to assign origins for a portion of the

368 problem birds could be caused by continued addition of elements to bone over large unknown

369 space over time. Second, adult starlings $>1$ year old, natal fingerprints may differ inter annually,

370 especially if foraging by such a generalist might change for different climatic years. Third,

371 problem birds could come from outside the region.

372 The problem bird contribution to vineyards and orchards in the southern part of the

373 Okanagan-Similkameen region was mostly from the northern end of the valley. It is likely that

374 the birds reared in the northern part of the valley move south as fruit ripens in the fall. The

375 remaining problem birds in vineyards and orchards are a mixture of local (southern) and

376 immigrant/unassigned birds. This is consistent with documented migration patterns in starling.

377 Generally, fall migration occurs from September to December (Kessel 1953; Dolbeer 1982).

378 The problem birds on dairy farms and feedlots were a mixture of immigrants/unassigned

379 and local birds. The high immigrant/unassigned population in the north Okanagan is likely

380 because these sites are close to unsampled source populations further to the north. During winter,

381 dairy farms and feedlots provide, adequate shelter and warmth and a diverse supply of food and

382 water (Palmer 1976). Several past studies have noted that the flocks of starlings increase in

383 number and concentrate on dairy farms and feedlots in winter (Palmer 1976; Glahn 1981).

384 Moreover, one of the challenges to this type of studies is that the trace element profiling is more 
385 difficult for wide-ranging, continuously distributed species as the number of potential source

386 areas is vast. If the organism migrates long distances, then trace elements alone might not be

387 sufficient to track their origin. Also trace elements alone would not be sufficient for tracking the

388 origin of migratory organisms that undertake large-scale movements and forage in diverse

389 geochemical environments. However, the combined use of trace elements and isotopes could

390 help track continental-scale movement patterns. Besides identifying bird origins, the trace

391 elemental signature could be used in several other ecological studies of birds, including matching

392 breeding populations with overwintering populations, tracking fine-scale dispersal (Poesel et al.

393 2008), identifying migratory connectivity (Szép et al. 2009) and identifying moulting areas (Szép

394 et al. 2003).

395

396 Conclusion starlings can be used to identify the natal origin of starlings with a high spatial resolution (10s of

$399 \mathrm{~km}$ ). The technique can be very effective in an area like the Okanagan-Similkameen region with

400 highly diverse geology. Most of the problem birds in vineyards and orchards of the south were

401 identified as local birds; very few were immigrants/unassigned. In contrast, in dairy farms and

402 feedlots in the north, most of the problem birds were identified as immigrants/unassigned to the

403 valley, probably because migration in fall/winter is generally southerly and the populations to the

404 north were not sampled. This study reveals that trace element fingerprints, a natural

405 environmental tracer, can track the origin of mobile organisms like starlings. Knowing the

406 origins of problem birds enables managers to make more informed decisions about how and

407 where to concentrate control efforts. 


\section{Acknowledgements}

409 We would like to thank Mr. David Arkinstall for his support in the trace analysis lab.

410 Thanks to Ms. Ashleigh Duffy, Mr. Kevin Kuemper and Dinesh Adhikary for their support

411 during field trips. The work was conducted in accordance with the ethics training requirements

412 of the Canadian Council on Animal Care (CCAC)/ National Institute Animal User Training

413 (NIAUT) program certificate number 7252-1 


\section{References:}

415BC Growers (2015) A Guide to BC's Agriculture Resources. The International Butler Academy 41674-162.

417BCGA (2008) Starling Control Program 2008 - A Year In Review. Grand Forks.

418BCGA. (2010). The Starling Control Program In the Okanagan Similkameen.

419BCGA (2012) Starling Control Program. British Columbia Grape Growers Association. BCGA 420(2013) A Starling Control Program for the Okanagan Similkameen. British Columbia Grape 421Growers Association.

422Boonen, Steven, Dirk Vanderschueren, Filip Callewaert, and Patrick Haentjens (2010) Aging and 423Bone Loss. Osteoporosis in Men 89(12):207-19.

424Boskey, Adele L (2007) Mineralization of Bones and Teeth. Elements 3:387-93.

425Cabe, Paul R. (1993) European Starling — Birds of North America Online. Issue No. 048.

426Canada, Environment (2013) Canadian Climate Normals 1981-2010 Station Data. Government of 427Canada.

428Canada, Natural Resources (2012) The Atlas of Canada - Geology and Geosciences.

429Chamberlain, C. P., Blum J.D., Holmes R. T. Xiahong Feng, Sherry T. W. Graves, G. R. (1997)

430The Use of Isotope Tracers for Identifying Populations of Migratory Birds.” Oecologia 109(1):13243141.

432Conover, M. R., Berryman, J. H., \& Dolbeer, R. A. (2007). Use of decoy traps to protect blueberries 433from juvenile European starlings. Human-Wildlife Confl Icts, 1(2), 265-270.

434Currey, John D (2004) Tensile Yield in Compact Bone Is Determined by Strain, Post-Yield 435Behaviour by Mineral Content. Biomechanics 37:549-56.

436Currey, John D., Kevin Brear, and Peter Zioupos (2004) Notch Sensitivity of Mammalian 
437Mineralized Tissues in Impact. Proceedings of the Royal Society B: Biological Sciences 271:51743822.

439David, M. (2010). Birds of Canada. Toronto: Dorling Kindersley Canada.

440Dolbeer, Richard A. (1982) Migration Patterns for Age and Sex Classes of Blackbirds and 441Starlings. Journal of Field Ornithology 53(1):28-46.

442Donovan, T., J. Buzas, P. Jones, and H. L. Gibbs (2006) Tracking Dispersal in Birds: Assessing the 443Potential of Elemental Markers. Auk 123(2):500-511.

444Dunnet, George M. (1955) The Breeding of the Starling sturnus Vulgaris in Relation to Its Food 445Supply. Ibis 97(4):618-62.

446Ethier, D. M., C. J. Kyle, T. K. Kyser, and J. J. Nocera (2013) Trace Elements in Claw Keratin as 447Temporally Explicit Indicators of Geographic Origin in Terrestrial Mammals. Annales Zoologici 448Fennici 50(1-2):89-99.

449Fowler, Jim, Lou Cohen, and Phil Jarvis. 1998. Practical Statistics for Field Biology. second. 450Hoboken: Wiley.

451Galgano, F., Favati, F., Caruso, M., Scarpa, T., \& Palma, A. (2008). Analysis of trace elements in 452southern Italian wines and their classification according to provenance. Food Science and 453Technology, 41, 1808-1815. https://doi.org/10.1016/j.lwt.2008.01.015

454Glahn, James F. (1981) Use Of Starlicide to Reduce Starling Damage at Livestock Feeding 455Operations. Pp. 273-77 in Great Plains Wildlife Damage Control Workshop Preceeding. Lincoln: 456University of Nebraska.

457Goitom Asfaha, D., Quétel, C. R., Thomas, F., Horacek, M., Wimmer, B., Heiss, G., ... 458Ueckermann, H. (2011). Combining isotopic signatures of $\mathrm{n}(87 \mathrm{Sr}) / \mathrm{n}(86 \mathrm{Sr})$ and light stable elements $459(\mathrm{C}, \mathrm{N}, \mathrm{O}, \mathrm{S})$ with multi-elemental profiling for the authentication of provenance of European cereal 
460samples. Journal of Cereal Science, 53(2), 170-177. https://doi.org/10.1016/j.jcs.2010.11.004 461Gómez-Díaz, Elena and Jacob González-Solís (2007) Geographic Assignment of Seabirds to Their 462Origin: Combining Morphologic, Genetic, and Biogeochemical Analyses. Ecological Applications 46317(5):1484-98.

464Greenough, J. D., H. P. Longerich, and S. E. Jackson (1997) Element Fingerprinting of Okanagan 465Valley Wines Using ICP - MS : Relationships between Wine Composition, Vineyard and Wine 466Colour. Australian Journal of Grape and Wine Research 3:75-83.

467Grynpas, Marc D., R. G. V. Hancock, C. Greenwood, J. Turnquist, and M. J. Kessler (1993) The 468Effects of Diet, Age, and Sex on the Mineral Content of Primate Bones. Calcified Tissue 469International 52(5):399-405.

470Hair, Joseph F., William C. Black, Barry J. Babin, and Rolph E. Anderson (2010) Multivariate Data 471Analysis a Global Perspective. 7th edn. London: Pearson United States.

472Hartigan, J. A. (1975) Clustering Algorithms. A Wiley Publication in Applied Statistics, New York 4731-351.

474Hobson, Keith A. (1999) Tracing Origins and Migration of Wildlife Using Stable Isotopes: A 475Review. Oecologia 120(3):314-26.

476Hobson, Keith A. (2005a) Stable Isotopes and the Determination of Avian Migratory Connectivity 477and Seasonal Interactions. The Auk 122(4):1037.

478Hobson, Keith A. (2005b) Using Stable Isotopes to Trace Long-Distance Dispersal in Birds and 479Other Taxa. Diversity and Distributions 11(2):157-64.

480Inger, Richard and Stuart Bearhop (2008) Applications of Stable Isotope Analyses to Avian 481Ecology. Ibis 150(3):447-61.

482Kelly, S., Heaton, K., \& Hoogewerff, J. (2005). Tracing the geographical origin of food: The 
483application of multi-element and multi-isotope analysis. Trends in Food Science \& Technology, 48416(12), 555-567. https://doi.org/10.1016/j.tifs.2005.08.008

485Kennedy, E. Dale and Harry W. Power (1990) Experiments on Indeterminate Laying in House 486Wrens and European Starlings. The Condor 92(4):861-65.

487Kerpez T. A., N. S. S. (1990). Competition between European starlings and native Woodpeckers for 488nest cavities in Saguaros. The Auk, 107(April), 367-375.

489Kessel, Brina (1953) Distribution and Migration of the European Starling in North America. The 490Condor 55(2):49-67.

491Kim, K. W., \& Thornton, I. (1993). Influence of uraniferous black shales on on the trace element 492composition of soils and food crops, Korea. Environmental Geochemistry and Health, 15(2-3), 493119-133. https://doi.org/10.1007/BF02627830

494Lachenbruch, P. A. and M. Goldstein (1979) Discriminant Analysis. BioMetrics 35(1):69-85. 495Lanocha, Natalia and Elzbieta Kalisinska (2012) Trace Metals and Micronutrients in Bone Tissues 496of the Red Fox Vulpes vulpes ( L ., 1758 ). Acta Theriol 57:233-44.

497Linz, George M., H. Jeffrey Homan, Shannon M. Gaulker, Linda B. Penry, and William J. Bleier 498(2007) European Starlings : A Review of an Invasive Species with Far-Reaching Impacts. Pp. 37849986 in Managing Vertebrate Invasive Species: Proceedings of an International Symposium. 500University of Nebraska.

501Lowe S., Browne M., Boudjelas S., P. D. M. (2004). 100 of the World's Worst Invasive Alien 502Species. A selection from the Global Invasive Species Database. Published by The Invasive Species 503Specialist Group ISSG a Specialist Group of the Species Survival Commission SSC of the World 504Conservation Union IUCN 12pp First Published as Special Liftout in Aliens, 12(3), 12.

505https://doi.org/10.1614/WT-04-126.1 
506Maechler, M., Rousseeuw, P., Struyf, A., Hubert, M., Hornik, K.(2017). Cluster: Cluster Analysis 507Basics and Extensions. R package version 2.1.0.

508Martin, R., Naftel, S., Nelson, A. J., \& Sapp, W. D. (2007). Comparison of the distributions of 509bromine, lead, and zinc in tooth and bone from an ancient Peruvian burial site by X-ray 510fluorescence 1. Can. J. Chem., 85, 831-836. https://doi.org/10.1139/V07-100

511Marsh, Jamesh H. (2015) Okanagan Valley - The Canadian Encyclopedia. Historica Canada. 512McKinney, R. (2004). Skull Pneumatization in Passerines: A Table of Last Dates Many Passerines 513in the Northeast Can be Aged Safely by Skulling. North American Bird Bander, 29(4), 164-170. 514Mueller, William P. and Charles M. Weise (1996) An Assessment of Age Determination Methods 515for Captured Passerine Birds. University of Wisconsin Milwaukee Field Satation, 21-27.

516Murtagh, Fionn and Pierre Legendre (2014) Ward's Hierarchical Agglomerative Clustering 517Method: Which Algorithms Implement Ward's Criterion? Journal of Classification 51831(October):274-95.

519National Audubon Society (2017). The $65^{\text {th }}$ to $114^{\text {th }}$ Christmas Bird Count 520Neuhauser, J. (2013) Using Trace Elements to Chemically Fingerprint European Starlings. 521M Sc. dissertation, Department of Earth, Environmental and Geographic Sciences, University of 522British Columbia Okanagan, British Columbia, Canada 523Norris D. R., D. B. Lank, J. Pither, D. Chipley, R. C. Ydenberg, T. K. (2007) Trace Element 524Profiles as Unique Identifiers of Western Sandpiper ( Calidris mauri ) Populations. Canadian 525Journal of Zoology 85:579-83.

526Norusis, M. J. (2016) IBM SPSS Statistics 24.0- SPSS Inc., Chicago. 527Okulitch, A. V. (2013) Geology, Okanagan Watershed, British Columbia. Geological Survey of 528Canada. 
529OSSCP (2014) Okanagan Similkameen Starling Control Program Report To the Regional District 530Okanagan-Similkameen.

531Palmer, Thomas K. (1976) Pest Bird Damage Control in Cattle Feedlots : The Integrated Systems 532Approach. in Vertbrate Pest Conference Procedings.

533Pasteris, Jill D., Brigitte Wopenka, and Eugenia Valsami-jones (2008) Bone and Tooth 534Mineralization : Why Apatite? Elements 4:97-104.

535Pimentel, David, Rodolfo Zuniga, and Doug Morrison (2005) Update on the Environmental and 536Economic Costs Associated with Alien-Invasive Species in the United States. Ecological 537Economics 52(3):273-88.

538Pinxten, Rianne, Marcel Eens, and Rudolf F. Verheyen (1994) Communal Breeding in the 539European Starling : Evidence from DNA Fingerprinting. American Ornithological Society 540111(2):482-86.

541Poesel, Angelika, A. Douglas Nelson, H. Lisle Gibbs, and W. John Olesik (2008) Use of Trace 542Element Analysis of Feathers as a Tool to Track Fine-Scale Dispersal in Birds. Behavioural 543Ecology and Sociobiology 63(1):153-58.

544R Development Core Team (2014) R: A Language and Environment for Statistical Computing. R 545Foundation for Statistical Computing, Vienna Austria.

546 Rogers, K. D. and P. Zioupos (1999) The Bone Tissue of the Rostrum of a Mesoplodon densirostris 547Whale: A Mammalian Biomineral Demonstrating Extreme Texture. Materials Science Letters 54818:651-54.

549Suthers, H. B. (1978). Analysis of resident flock of starlings. Bird Banding Winter 1978. 550Suzuki, Ryota and Hidetoshi Shimodaira (2014) Hierarchical Clustering with P-Vlaues via 551Multiscale Bootstrap Resampling: Package ' Pvclust' . 
552Szép, T., K. A. Hobson, J. Vallner, S.E. Piper, B. Kovács, D. Z. Szabó, A. P. Moller (2009)

553Comparison of Trace Element and Stable Isotope Approaches to the Study of Migratory 554Connectivity: An Example Using Two Hirundine Species Breeding in Europe and Wintering in 555Africa.” Journal of Ornithology 150(3):621-36.

556Szép, T., A. P. Moller, J. Vallner, A. Kovacs, and D. Norman (2003) Use of Trace Elements in 557Feathers of Sand Martin Riparia riparia for Identifying Moulting Areas.” Journal of Avian Biology 55834(3):307-20.

559Tieszen, L. L., T. W. Boutton, K. G. Tesdahl, and N. A. Slade. (1983) Fractionation and Turnover 560of Stable Carbon Isotopes in Animal Tissues: Implications for 13C Analysis of Diet. Oecologia 56157(1-2):32-37.

562Tinbergen, J. M. (1981) Foraging Decisions in Starlings Sturnus Vulgaris. Ardea 69:1-67.

563Virgo, B. B. (1971). Bird damage to sweet cherries in the Niagara Peninsula, Ontario. Plant 564Science, 423, 415-423.

565Vuilleumier, François. 2009. Birds of North America.

566Ward, Joe H (1963) Hierarchical Grouping to Optimize an Objective Function. American Statistical 567Association 58(301):236-44.

568National Audubon Society (2010). The Christmas Bird Count Historical Results. 
Figure 1

Map of the study area (Okanagan-Similkameen region) with sampling sites in British Columbia (BC), Canada.

Filled black circles represent sampling sites for juvenile starlings, whereas, unfilled black circles represent sampling sites for adult starlings. Black circles with black dots represent the sampling sites where both adults and juveniles were collected.

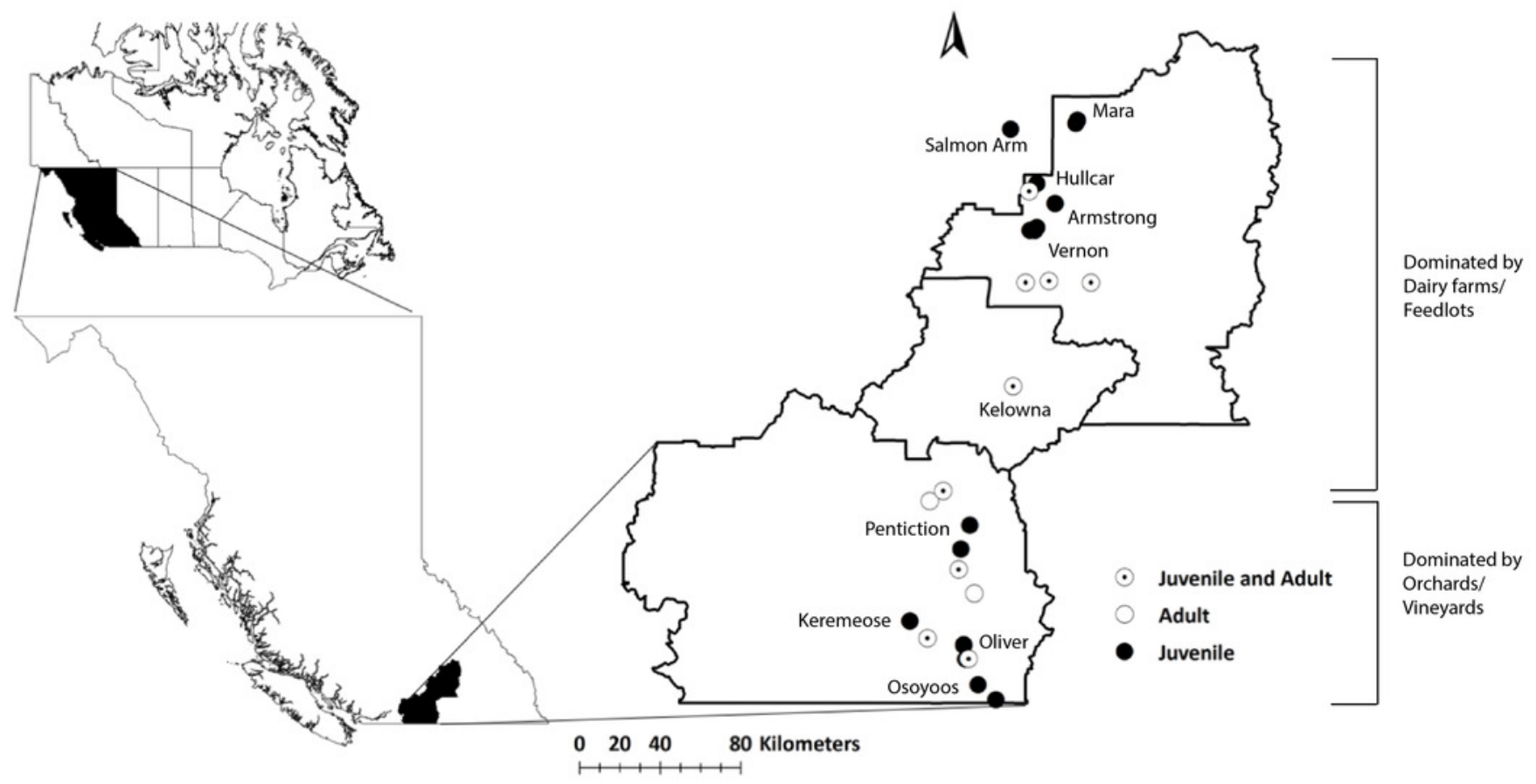




\section{Figure 2}

Distribution of juvenile starlings caught in different locations in the OkanaganSimilkameen region, British Columbia.

Stepwise discriminant analysis of juvenile starlings $(n=105)$ from 10 different locations based on first two canonical discriminant functions $(r c=0.07, \mathrm{P}<0.0001)$ calculated from 20 trace elements. Different color represents different sampling area, and the black square represents the centroid of each sampling area.

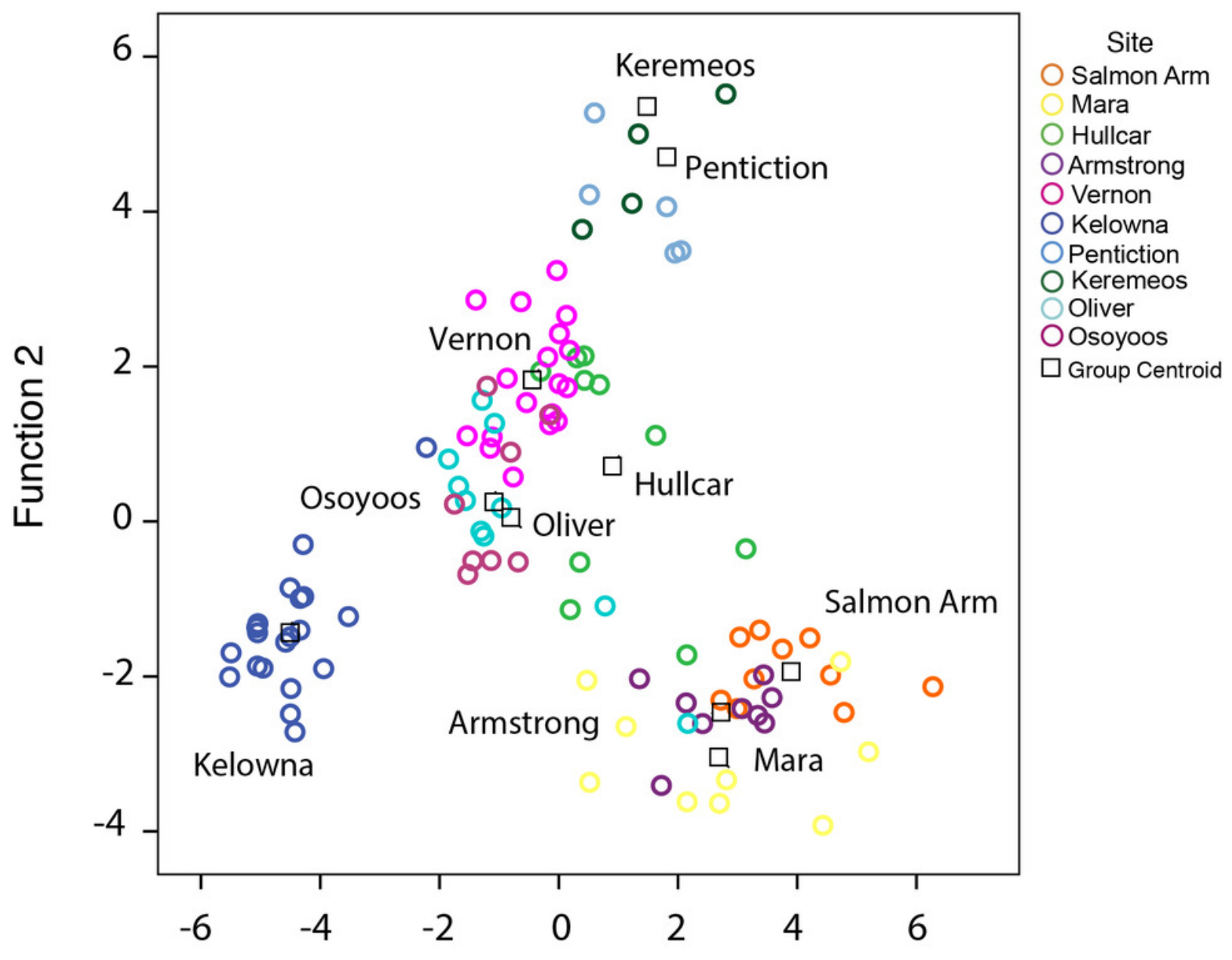

Function 1 
Figure 3

Cluster analysis of juvenile starlings.

Cluster analysis of juvenile starlings $(n=105)$ sampled in the Okanagan-Similkameen region based on Ward.D method derived from the Euclidean distance using 20 elements. The distance provides a relative measure of how different the clusters are in relation to each other. Different colour represents different locations in the Okanagan-Similkameen region, British Columbia.

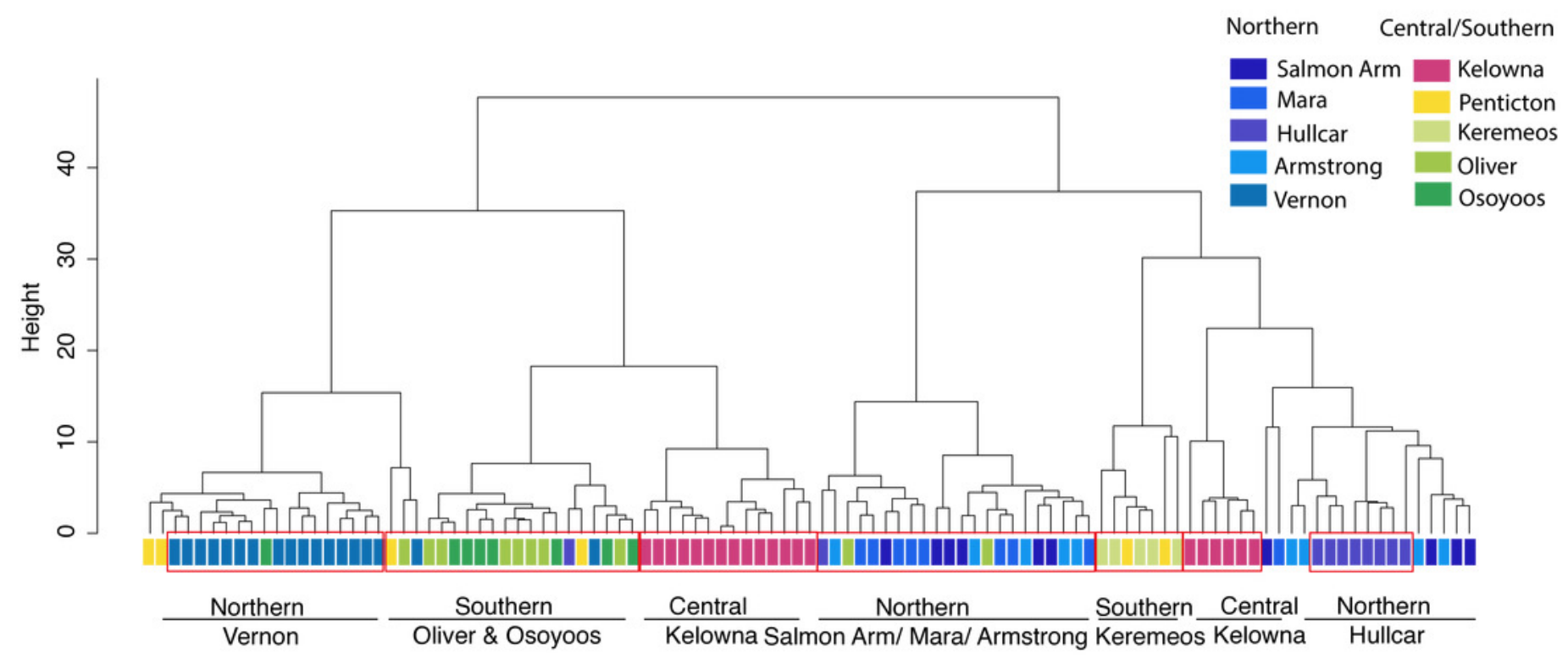


Figure 4

Cluster analysis of juvenile and adult starlings.

Cluster analysis of juvenile and adult $(n=223)$ birds collected in different locations in the Okanagan-Similkameen region, British Columbia based on Ward.D method derived from the Euclidean distance using 20 elements. Orange color represents immigrant adult adults, dark blue colours represent samples from the northernmost area, and the colour fades as the location moves towards the south.

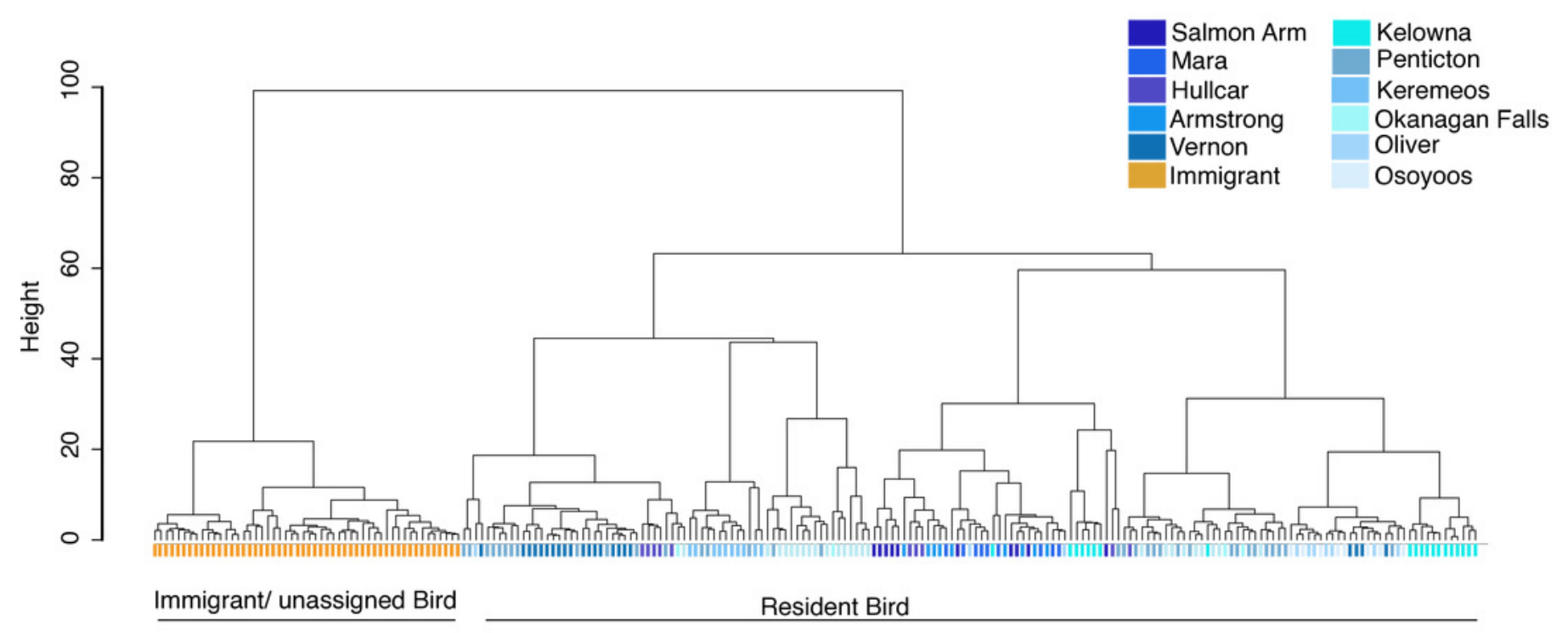


Figure 5

Map of the origin of the source population of problem birds caught in vineyards /orchards and dairy farms/feedlots in the Okanagan-Similkameen region, British Columbia.

The radius of the circle depends on the percentage contributed from particular sites. 


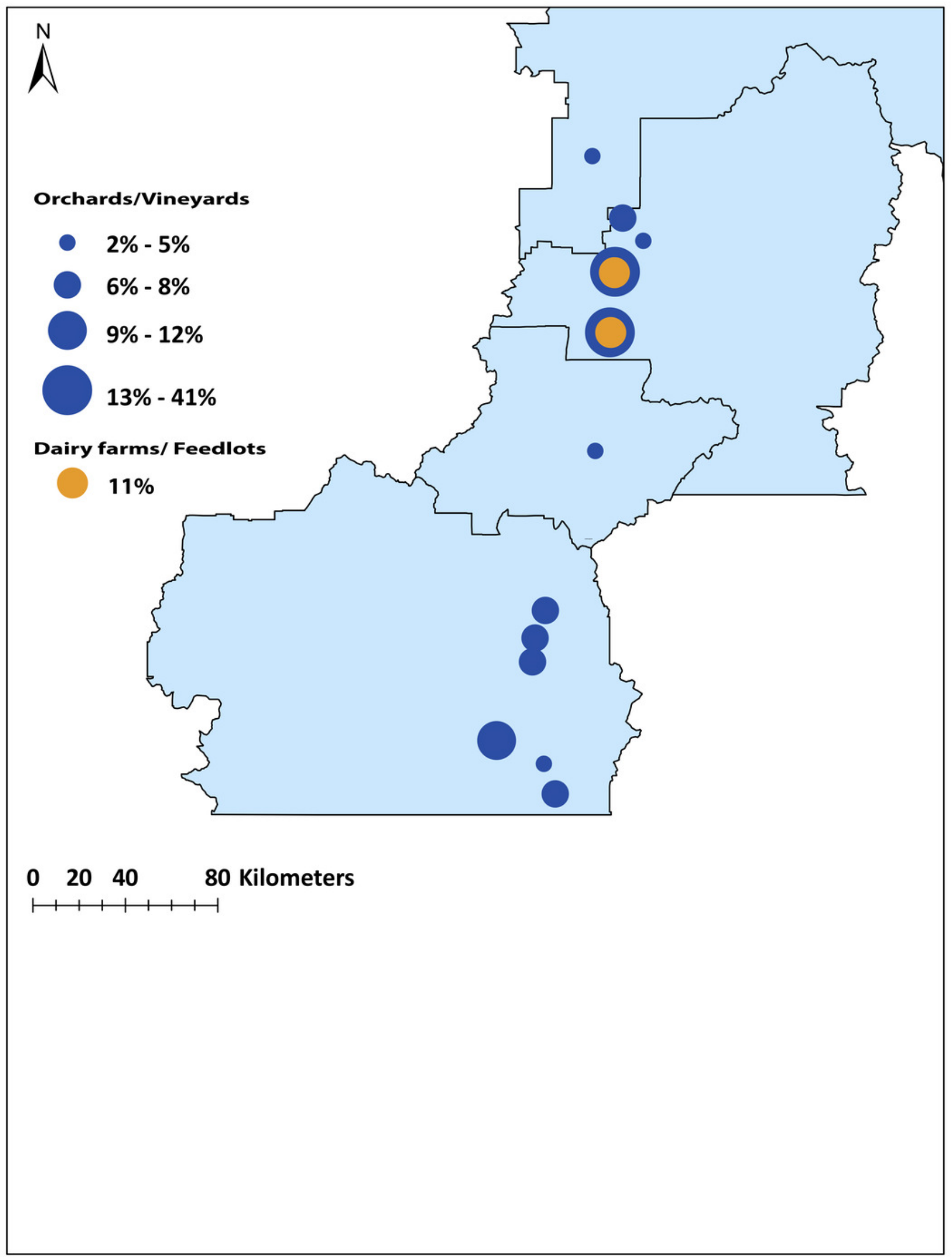




\section{Table $\mathbf{1}$ (on next page)}

Classification results for juvenile starlings to its predicted locations in the OkanaganSimilkameen region, British Columbia.

The predicted group membership shows the percentage of correctly classified samples, based on the cross-validation function in the SPSS software package where $79.0 \%$ of original grouped cases correctly classified. 


\begin{tabular}{|c|c|c|c|c|c|c|c|c|c|c|c|c|}
\hline \multirow[t]{2}{*}{ Year } & \multirow[b]{2}{*}{ Site } & \multicolumn{11}{|c|}{ Predicted Group Membership (\%) } \\
\hline & & Kelowna & Hullcar & $\begin{array}{c}\text { Salmon } \\
\text { Arm }\end{array}$ & Armstrong & Mara & Vernon & Oliver & Osoyoos & $\begin{array}{c}\text { Penticton/ } \\
\text { Summerland }\end{array}$ & Keremeos & $\begin{array}{c}\text { No of } \\
\text { Sample }\end{array}$ \\
\hline \multirow[t]{10}{*}{2015} & Kelowna & 95 & 0 & 0 & 0 & 0 & 5 & 0 & 0 & 0 & 0 & 20 \\
\hline & Hullcar & 0 & 90 & 0 & 0 & 0 & 0 & 0 & 10 & 0 & 0 & 10 \\
\hline & $\begin{array}{c}\text { Salmon } \\
\text { Arm }\end{array}$ & 0 & 0 & 70 & 20 & 10 & 0 & 0 & 0 & 0 & 0 & 10 \\
\hline & $\begin{array}{c}\text { Armstron } \\
\mathrm{g}\end{array}$ & 0 & 0 & 0 & 78 & 22 & 0 & 0 & 0 & 0 & 0 & 9 \\
\hline & Mara & 0 & 0 & 0 & 33 & 67 & 0 & 0 & 0 & 0 & 0 & 9 \\
\hline & Vernon & 0 & 0 & 0 & 0 & 0 & 100 & 0 & 0 & 0 & 0 & 18 \\
\hline & Oliver & 0 & 0 & 0 & 0 & 10 & 0 & 60 & 30 & 0 & 0 & 10 \\
\hline & Osoyoos & 0 & 0 & 0 & 0 & 0 & 37 & 37 & 25 & 0 & 0 & 8 \\
\hline & Penticton & 0 & 0 & 0 & 0 & 0 & 0 & 0 & 0 & 67 & 33 & 6 \\
\hline & Keremeos & 0 & 0 & 0 & 0 & 0 & 0 & 0 & 0 & 0 & 100 & 5 \\
\hline
\end{tabular}

